\title{
Prevalence of Diseases in Pilgrims Referring to Iranian Clinics in Iraq
}

\author{
Javad Mousavi ${ }^{1}$, Fatemeh Jafari ${ }^{2,}$ * \\ ${ }^{1}$ Zanjan Blood Transfusion Center, Zanjan University of Medical Sciences, Zanjan, IR Iran \\ ${ }^{2}$ Zanjan University of Medical Sciences, Zanjan, IR Iran
}

*Corresponding Author: Fatemeh Jafari, Zanjan University of Medical Sciences, Zanjan, Iran. Email: fjafari@ zums.ac.ir

\begin{abstract}
Introduction: Every year a large number of Muslims, especially from Iran, travel to holy places in Iraq for pilgrimage. Like Hajj and other mass gatherings, the health of pilgrims in Iraq is a major issue. This study aimed to determine the prevalence of diseases in pilgrims referring to Iranian clinics in Iraq.

Methods: This descriptive study was conducted in April and May, 2013. All Iranian pilgrims referring to clinics in Najaf, Karbala, Baghdad, or Kazmain during this one-month period were entered in the study. Data was gathered from medical records in these clinics and analyzed using SPSS software version 16 .

Results: From 22 April to 20 May, 2013, a total of 26,574 patients were admitted to Iranian clinics in Iraq, 42\% of whom were women and 58\% were men. The main causes for referring to the clinics were signs and symptoms of acute respiratory infection (48\%), musculoskeletal problems (19\%), control of underlying disease (diabetes, cardiovascular disease, hypertension, gastritis) (16\%), and gastroenteritis (7\%). The prevalence of underlying conditions was higher in women.

Conclusion: According to the survey results and specific conditions in terms of climate and the infrastructure of facilities in Iraq, it seems that infectious and communicable diseases can be prevented by providing appropriate training prior to the pilgrimage and emphasizing and monitoring the use of personal protective equipment. Moreover, vaccination, medical examination before deployment, and establishing medical records can be better ways to treat underlying diseases, control health, and ensure the better health of pilgrims.

Keywords: Prevalence, Disease, Travel, Muslim
\end{abstract}

Article History: Received: 19 Oct. 2015; Accepted: 20 Des. 2015; Online Published: 10 Apr. 2016

Cite this article as: Mousavi J, Jafari F. Prevalence of diseases in pilgrims referring to Iranian clinics in Iraq. Int J Travel Med Glob Health. 2016;4(1):31-3.

\section{Introduction}

Every year a large number of Muslims, especially from Iran, travel to holy places in Iraq for pilgrimage. During Hajj and other mass gatherings, the health of pilgrims to Iraq is a serious matter due to overcrowding and the excess heat [1]. Infectious diseases, especially acute respiratory tract infections, are a major problem during pilgrimages and are the most common cause for admission to clinics [2, 3]. The large population density during pilgrimage, especially in the months of Moharram and Safar, prepares prime conditions for a local outbreak and the cross-country spread of infectious agents [4].

If necessary arrangements are not made, every trip can be accompanied by a number of risks, but travel to Iraq has very high importance and sensitivity. In recent decades, domestic and foreign wars in this country have had deleterious effects on infrastructures like healthcare systems, water supply, sewage treatment, and the industry of tourism. Despite numerous problems and shortcomings, the number of pilgrims is increasing day by day because of a relative increase in social security. Furthermore, due to the lack of necessary rules and constraints, there are no prohibitions for travel by children, pregnant women, disabled and elderly people, and those suffering chronically debilitating diseases such as heart disease who, because of one's physical condition or weakened immune system, are more at risk. Obviously, protecting the health and safety of pilgrims in such circumstances becomes a very serious challenge.

The Hajj Medical Center of the Iranian Red Crescent Society provides free healthcare to all pilgrims during their pilgrimage and implements stringent infection control measures. At least 9 healthcare centers in the vicinity of the pilgrimage places are equipped with the latest emergency management medical systems and staffed with at least 120 specialized personnel who provide suitable healthcare to all pilgrims 24 hours a day, free of charge.

This study has examined the prevalence of disease among pilgrims to Iraq and the clinics affiliated with the pilgrimage center in Iraq. To the best of the authors' knowledge, this is the first study to evaluate the prevalence of disease among pilgrims to Iraq. Results of this study will help planners and related officials promote healthcare and reduce morbidity or progression of previous underlying diseases in pilgrims.

\section{Methods}

This descriptive study evaluated the prevalence of disease and common health hazards among Iranian pilgrims in Iraq. This study was carried out in the Iranian clinics of Najaf, Karbala, Kazmain, Baghdad in April and May, 2013. The convenience sampling method was used. All Iranian pilgrims, officials, and staff of Iranian travel agencies referring to these clinics because of disease were entered in the study; non-Iranian patients were excluded. Data was collected using a checklist that covered the age, sex, disease diagnosis, treatment, and final diagnosis of patients who died or referred to hospitals for inpatient care. This study was conducted in collaboration with 30 physicians. They were asked to document the required information carefully. Data was analyzed using SPSS software version 16.

\section{Results}

All patients had state-financed full health insurance coverage during their journey, and all healthcare services, including medications and even hospitalizations, were free of charge. A total number of 27,836 patients referred to the Medical Center of Iran's Hajj and Pilgrimage in the cities of Najaf, Karbala, Kazmain, and Baghdad during the study. Of these, 1,262 were non-Iranian people and were excluded 
from the study; thus, a total of 26,574 people, $42 \%$ female and $58 \%$ male, comprised the study sample. They had a median age of 58 years (ranging from 6 months to 94 years).

The main reasons for referral to the clinics were signs and symptoms of acute respiratory tract infection including sore throat and throat irritation (26\%), cough (21\%), runny nose, nasal congestion, asthma and dyspnea ( $2 \%)$, musculoskeletal problems including pain (leg pain, back pain) and muscle spasms (19\%), control of underlying disease (diabetes, cardiovascular disease, hypertension, gastritis) (16\%), and gastroenteritis $(7 \%)$. Other causes for referral were skin lesions, especially allergy lesions and sunburn, vaginal bleeding due to menstruation, trauma, and heat stress.

Results showed that hypertension, in $24.7 \%$ cases, was the most common chronic or underlying disease among referred patients, and diabetes with $13.4 \%$ and cardiovascular diseases with $12.3 \%$ prevalence were second and third (Figure 1).

The prevalence of chronic respiratory diseases, including COPD and asthma, cardiovascular diseases, and hyperlipidemia was higher in men compared to women. In contrast, the prevalence of hypertension, diabetes, and musculoskeletal disease was higher in women (Figure 2).

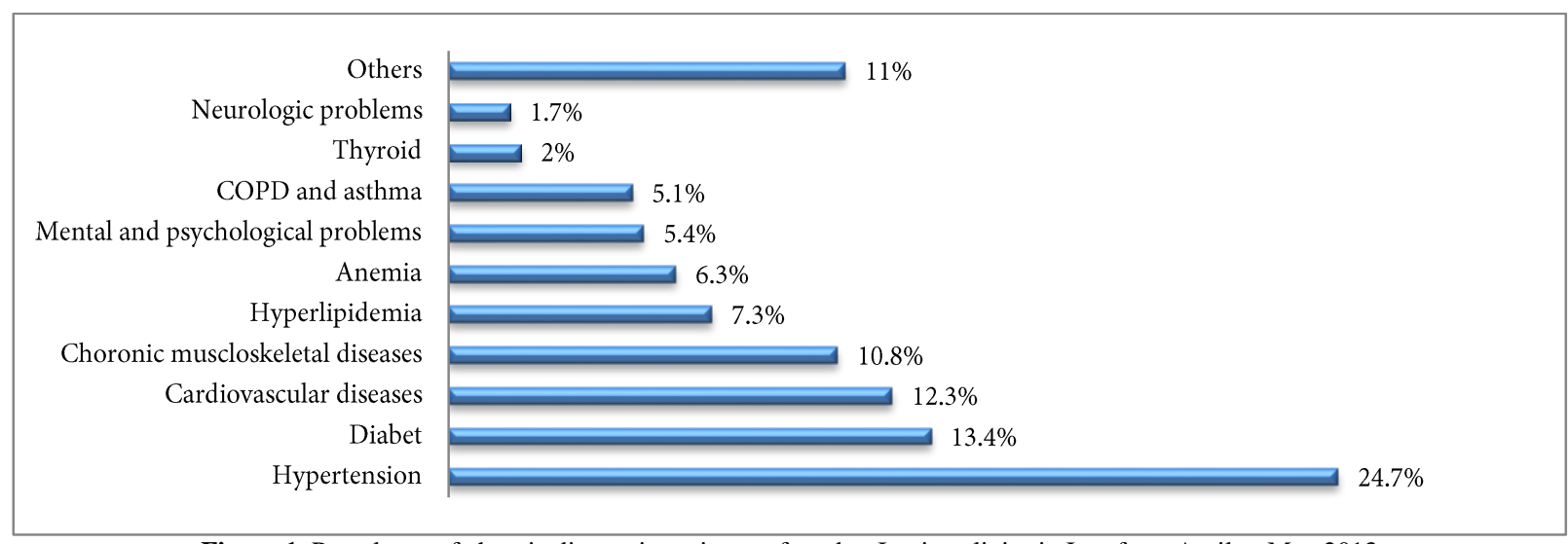

Figure 1. Prevalence of chronic disease in patients referred to Iranian clinics in Iraq from April to May 2013

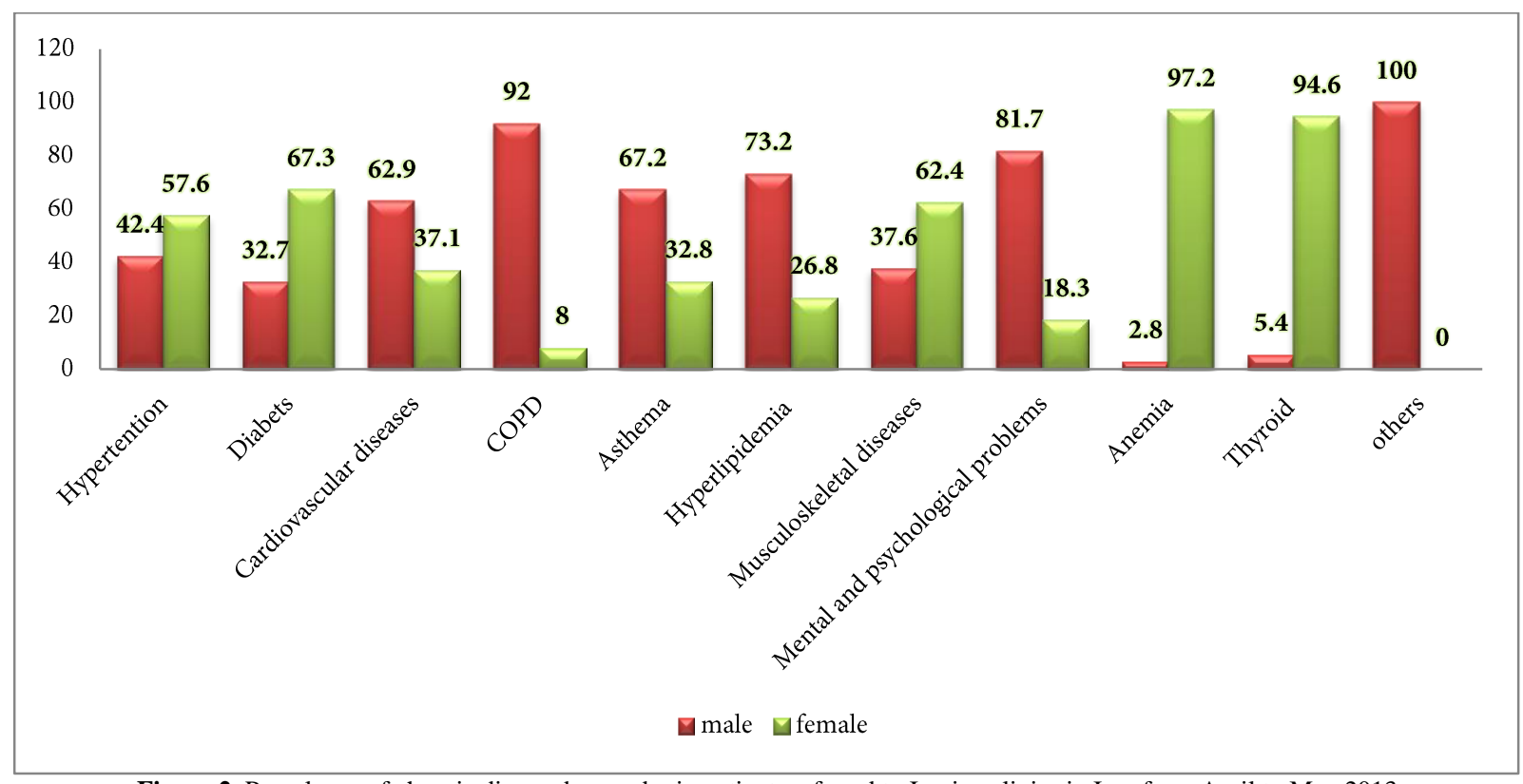

Figure 2. Prevalence of chronic disease by gender in patients referred to Iranian clinics in Iraq from April to May 2013

There was no difference between women and men in the context of respiratory and digestive system diseases, including acute respiratory infection and gastroenteritis.

\section{Discussion}

The current study was restricted to a limited time of one month. The results cannot be extrapolated to other months or seasons of the year, because prevalence of diseases varies in different months. This study can provide valuable information for authorities and practitioners about pilgrim health. Among patients who referred to clinics during the study, less than $1 \%$ were hospitalized and only 4 patients died. This is less than in an Iranian study in Saudi Arabia where $1.3 \%$ of individuals were hospitalized [5]. Maybe this difference is attributable to duration of stay and less overcrowding in Iraq despite the more suitable conditions in Saudi Arabia.

The most common complaints during the pilgrimage were sore throat and cough with $(26 \%)$ and $(21 \%)$ attack rates, respectively. These results are consistent with those from other studies of pilgrims that have shown cough to be the main complaint among pilgrims (attack rate of 51\%) $[6,7]$.

Acute respiratory tract infection (ARI) was the most common disease in this study (prevalence rate 49\%). In accordance with these results, studies of Hajj pilgrims have shown that respiratory tract infection is the most common disease among pilgrims (prevalence rate of 70\%) [8]. Close contact of pilgrims during their stay in Iraq, their shared 
sleeping accommodations, and the dusty air increase the risk of airborne respiratory disease transmission.

Influenza-like illnesses have an important role in the occurrence of ARIs. Prevalence of disease in people who have been vaccinated has fallen considerably $[9,10]$; therefore, it is recommended that all pilgrims be vaccinated against these diseases before they travel. Personal hygiene, especially frequent hand washing and use of a face mask, can also prevent disease transmission.

Because of the high prevalence of gastroenteritis (7\%) and outbreak probability, food preparation should be more closely monitored, and the related personnel should be advised to observe personal hygiene principles. A recent systematic review showed that gastrointestinal diseases, food-poisoning, and diarrhea continue to occur among pilgrims [11].

In the current study, the prevalence of musculoskeletal problems such as pain in the legs and back and muscle spasm was considerable. The long journey by bus, intensive and long programs for pilgrimage in Iraq, and caducity in most pilgrims can explain this result.

Although this study was not conducted during the warmest season and heat stress was not a great problem, heat exhaustion and heatstroke can be harmful and could become a major cause of morbidity and mortality in pilgrims, particularly in summer. Therefore, appropriate precautions should be taken.

In accordance with other studies, the current study showed ageing and previous underlying medical conditions such as diabetes, hypertension, and chronic pulmonary diseases in most of pilgrims as being great problems [7]. Medical examinations conducted prior to deployment, pre-travel education and advice on compliance with continuing previous medication, organizing medical records, and periodical examinations during the trip can prevent the exacerbation of an underlying disease. Because of health conditions in Iraq including heat, crowding, and long and intensive pilgrimage programs, decrepit, elderly, and disabled individuals should be considered as a high-risk population and be limited for pilgrimage as much as possible. Fortunately, two super specialty hospitals in Karbala and Najaf are being built; they will resolve many patient problems favorably after establishment.

\section{Conclusion}

This was the first study to evaluate the prevalence of disease in pilgrims of Iraq. Chronic medical conditions including hypertension, diabetes and cardiovascular diseases were found to be the most prevalent health problems. Based on the results of this study and considering the specific conditions climate and infrastructure facilities in Iraq, it seems that infectious and communicable diseases can be prevented by providing pilgrims with appropriate training prior to the pilgrimage and emphasizing and monitoring the use of personal protective equipment. Vaccination and medical examination before traveling and the establishment of medical records can improve the treatment of underlying disease and control of health.

\section{Acknowledgements}

The authors appreciate the cooperation of all physicians in the Iranian clinics of Najaf, Karbala, Kazmain, and Baghdad during the study period.

\section{Authors' Contributions}

Javad Mousavi: Study concept and design, acquisition of data, study supervision, drafting of the manuscript

Fatemeh Jafari: statistical analysis, interpretation of data, critical revision of the manuscript

\section{Financial Disclosure}

The authors declare no financial disclosures.

\section{Funding/Support}

This study was supported by the Zanjan University of Medical Sciences.

\section{References}

1. Memish ZA. The Hajj: communicable and non-communicable health hazards and current guidance for pilgrims. Euro Surveill. 2010;15(39):19671.

2. Haworth E, Barasheed O, Memish ZA, Rashid H, Booy R. Prevention of influenza at Hajj: applications for mass gatherings. J R Soc Med. 2013;106(6):215-23.

3. Khan K, Memish ZA, Chabbra A, Liauw J, Hu W, Janes DA, et al. Global public health implications of a mass gathering in Mecca, Saudi Arabia during the midst of an influenza pandemic. J Travel Med. 2010;17(2):75-81.

4. Memish ZA, Zumla A, Alhakeem RF, Assiri A, Turkestani A, Al Harby KD, et al. Hajj: infectious disease surveillance and control. Lancet. 2014;383(9934):2073-82.

5. Meysamie A, Ardakani HZ, Razavi SM, Doroodi T. Comparison of mortality and morbidity rates among Iranian pilgrims in Hajj 2004 and 2005. Saudi Med J. 2006;27(7):1049-53.

6. Gautret P, Yong W, Soula G, Gaudart J, Delmont J, Dia A, et al. Incidence of Hajj-associated febrile cough episodes among French pilgrims: a prospective cohort study on the influence of statin use and risk factors. Clinical microbiology and infection : the official publication of the European Society of Clinical Microbiology and Infectious Diseases. 2009;15(4):335-40.

7. Gautret P, Soula G, Delmont J, Parola P, Brouqui P. Common health hazards in French pilgrims during the Hajj of 2007: a prospective cohort study. J Travel Med. 2009;16(6):377-81.

8. Choudhry AJ, Al-Mudaimegh KS, Turkistani AM, Al-Hamdan NA. Hajj-associated acute respiratory infection among hajjis from Riyadh. East Mediterr Health J. 2006;12(3-4):300-9.

9. Alfelali M, Barasheed O, Tashani M, Azeem MI, El Bashir H, Memish ZA, et al. Changes in the prevalence of influenza-like illness and influenza vaccine uptake among Hajj pilgrims: A 10-year retrospective analysis of data. Vaccine. 2015;33(22):2562-9.

10. Barasheed O, Rashid H, Heron L, Ridda I, Haworth E, Nguyen-VanTam J, et al. Influenza vaccination among Australian Hajj pilgrims: uptake, attitudes, and barriers. J Travel Med. 2014;21(6):384-90.

11. Gautret P, Benkouiten S, Sridhar S, Al-Tawfiq JA, Memish ZA. Diarrhea at the Hajj and Umrah. Travel Med Infect Dis. 2015;13(2):159-66 